\title{
X. On transient electric current produced by suddenly twisting magnetized iron and nickel wires
}

\section{H. Nagaoka}

To cite this article: H. Nagaoka (1890) X. On transient electric current produced by suddenly twisting magnetized iron and nickel wires, Philosophical Magazine Series 5, 29:176, 123-133, DOI: $10.1080 / 14786449008619910$

To link to this article: http://dx.doi.org/10.1080/14786449008619910

曲 Published online: 14 Oct 2011.

Submit your article to this journal $[\pi$

Џll Article views: 4

Q View related articles $\square$

Citing articles: 2 View citing articles $\square$ 
On Transient Electric Current from Iron and Nickel. 123

As far as terms of the order $e^{-(2 n+10)}$ inclusive, $-u \iint \mathrm{P}_{n} \phi_{\mathrm{A}} d \mathrm{~S}_{\mathrm{i}}$ is made up of the term

$$
\begin{aligned}
\frac{4 \pi a^{2 n+4} b^{3} u^{2}}{c^{2 n+4}}\left\{\frac{1}{2 !}\right. & +\frac{(n+2)^{2}}{3 !} \frac{b^{2}}{c^{2}}+\frac{(n+2)^{2}(n+3)^{2}}{4 ! 2 !} \frac{b^{4}}{c^{4}} \\
& \left.+\frac{(n+2)^{2}(n+3)^{2}(n+4)^{2}}{5 ! 3 !} \frac{b^{5}}{c^{6}}+\ldots\right\}
\end{aligned}
$$

due to the images $P$ and $Q$, together with the term

$$
\frac{2 \pi a^{2 n+4} a^{3} b^{6} u^{2}}{c^{2 n+10}}
$$

due to the image $R$.

By interchanging $m$ and $n, u$ and $v, a$ and $b$, the remaining term on the right-hand side of (10) can be found.

If the vibrating spheres consist of liquid of density $\rho^{\prime}$, the velocity-potential within $\mathrm{X}$ is $u \mathrm{P}_{n} r^{n} / n a^{n-1}$, and the kinetic energy of the sphere $\mathrm{X}$ is $\frac{2 \pi \rho^{\prime} a^{3} u^{2}}{n(2 n+1)}$. A similar expression holds for the other sphere.

When $c$ is constant the principal term in the expression of the stress between the spheres varies as $c^{-(m+n+2)}$ or as $c^{-(2 n+5)}$, or as $c^{-(2 m+5)}$.

If $u, v$ are simple harmonic functions of the time, the average stress between the spheres is to be found as before.

The case when $m=n=1$ has been discussed by Mr. Hicks (loc. cit.); for all other values of $m$ and $n$ the centres of the spheres are at rest.

X. On Transient Electric Current produced by suddenly twisting Magnetized Iron and Nickel Wires. By H. NAGAora, Rigakusi, of Imperial University, Tokyo*.

[Plate II.]

TN a recent number of Wiedemann's Annalen, Herr 1 Zehnder $\dagger$ communicated the result of his experiments on the transient current produced by twisting magnetized iron and nickel wires, in which he finds the direction of current in nickel to be opposite to that in iron. The same result had been already known to me since July 1888. Being engaged in

* Communicated by Sir William Thomson.

$\dagger$ "Ueber Deformationsströme." Wiedemann's Annalen, Bd. xxxriii. p. 68 . This number reached me on 14 th October, 1889. 


\section{H. Nagaoka on Transient Electric Current produced}

the investigation of the effect of twist in the magnetization of nickel and iron, I tried some preliminary experiments on the transient current produced by twisting magnetized wires. Thereby I hoped to trace some connexion between the transient current thus observed and the reversal of polarity * produced by twisting magnetized nickel wire, which is at the same time subjected to longitudinal stress. Though nothing striking was obtained in this direction, results not hitherto made known by the researches of Matteucci $\dagger$ and Ewing $\ddagger$ were obtained. The following is the description of the experiments made in July and September, 1888.

The wire to be examined was well annealed and hung in a magnetizing solenoid. The coil was 30 centim. long and wound in 12 layers of thick copper wire, giving a magnetizing field of 36.7 units for a current of one ampere. The upper end of the wire was held fixed, while the lower was attached to a twisting apparatus provided with a graduated circle and a pointer. The two extremities of the wire were electrically connected to a low-resistance ballistic mirrorgalvanometer. The transient current was measured by the first swing of the galvanometer. The deflexion was read after suddenly twisting the wire between two extreme limits of twist. Generally, it was after a number of twistings in both ways from the initial position of no twist, that the transient current settled to its final value.

Since the present investigation was undertaken with a view to ascertain the relation, if such exists, between this transient current and the reversal of polarity, the effect of longitudinal stress on the transient current was also looked into, as this played an important part in producing the reversal mentioned.

A nickel wire 30 centim. long and 0.5 millim. in radius was treated in the way above mentioned, the angle of twist amounting to $60^{\circ}$ in both directions from the initial position of no twisting. The first experiment was performed under no longitudinal stress; the transient current produced by suddenly twisting the wire in various magnetizing fields was measured, the field being gradually increased from 0 to 110

* See "Effects of Torsion and Longitudinal Stress on the Magnetization of Nickel," Journ. of the Coll. of Science, Imp. Univ., Japan, vol, ii., or Phil. Mag. Feb. 1889; and also "Effect of Twist on the Magnetization of Iron and Nickel," Journ. of the Coll. of Science, vol. iii. At the end of the latter paper a short sketch of the results on the transient current is given.

$\dagger$ See Wiedemann's Electricität, Bd. iii. $\$ 771$.

† Proc. Roy. Soc. vol. xxxvi. 1884. 
by twisting Magnetized Iron and Nickel Wires.

C.G.S. units (July 5, 1888). The following Table gives the readings of the first swing in different magnetizing fields :-

Nickel wire $\left(r=.5\right.$ millim., $l=30$ centim., $\left.\tau= \pm 60^{\circ}\right)$.

Unloaded.

\begin{tabular}{|c|c|c|c|}
\hline $\mathfrak{y}$. & $\begin{array}{c}\text { Reading of } \\
\text { ballistic } \\
\text { galvanometer. }\end{array}$ & $\mathfrak{5}$. & $\begin{array}{c}\text { Reading of } \\
\text { ballistic } \\
\text { galvanometer. }\end{array}$ \\
\hline$\cdot 21$ & 7 & $13 \cdot 8$ & 149 \\
$\cdot 34$ & 15 & $19 \cdot 9$ & 151 \\
$\cdot 71$ & 26 & $31 \cdot 7$ & 152 \\
$1 \cdot 14$ & 45 & $40 \cdot 7$ & 149 \\
$2 \cdot 01$ & 85 & $48 \cdot 8$ & 145 \\
$3 \cdot 63$ & 107 & $61 \cdot 0$ & 142 \\
$4 \cdot 74$ & 122 & $75 \cdot 6$ & 136 \\
6.82 & 135 & 1100 & 124 \\
$9 \cdot 95$ & 144 & & \\
\hline
\end{tabular}

The result is shown graphically in Plate II. fig. 1. Examining the curve we see that the current increases rapidly in low magnetizing fields; but as the magnetizing force becomes greater the increase takes place very slowly, passes a maximum, and begins to diminish nearly in a straight line.

On loading the wire and going through the same series of operations, the following readings of the deflexion were taken :-

Nickel wire $\left(r=.5\right.$ millim., $l=30$ centim., $\left.\tau= \pm 60^{\circ}\right)$.

Loaded $3 \mathrm{kgs}$.

\begin{tabular}{|c|c|}
\hline $\mathfrak{S}$. & $\begin{array}{c}\text { Reading of } \\
\text { ballistic } \\
\text { galvanometer. }\end{array}$ \\
\hline$\cdot 71$ & 3 \\
$1 \cdot 0$ & 8 \\
$3 \cdot 6$ & 30 \\
$6 \cdot 8$ & 64 \\
$10 \cdot 0$ & 98 \\
$19 \cdot 9$ & 140 \\
$31 \cdot 8$ & 154 \\
$41 \cdot 0$ & 159 \\
$49 \cdot 1$ & 161 \\
60.6 & 160 \\
$83 \cdot 0$ & 158 \\
\hline
\end{tabular}

Loaded $6 \mathrm{kgs}$.

\begin{tabular}{|c|c|}
\hline $\mathfrak{S}$. & $\begin{array}{c}\text { Reading of } \\
\text { ballistic } \\
\text { galvanometer. }\end{array}$ \\
\hline $1 \cdot 1$ & 7 \\
$3 \cdot 6$ & 16 \\
$7 \cdot 4$ & 35 \\
$16 \cdot 8$ & 87 \\
$24 \cdot 1$ & 129 \\
$31 \cdot 8$ & 146 \\
$40 \cdot 7$ & 155 \\
$51 \cdot 0$ & 165 \\
$68 \cdot 7$ & 168 \\
$85 \cdot 8$ & 167 \\
& \\
\hline
\end{tabular}

The above readings are plotted in fig. 1 , from which we see that although the essential form of the curve is not 


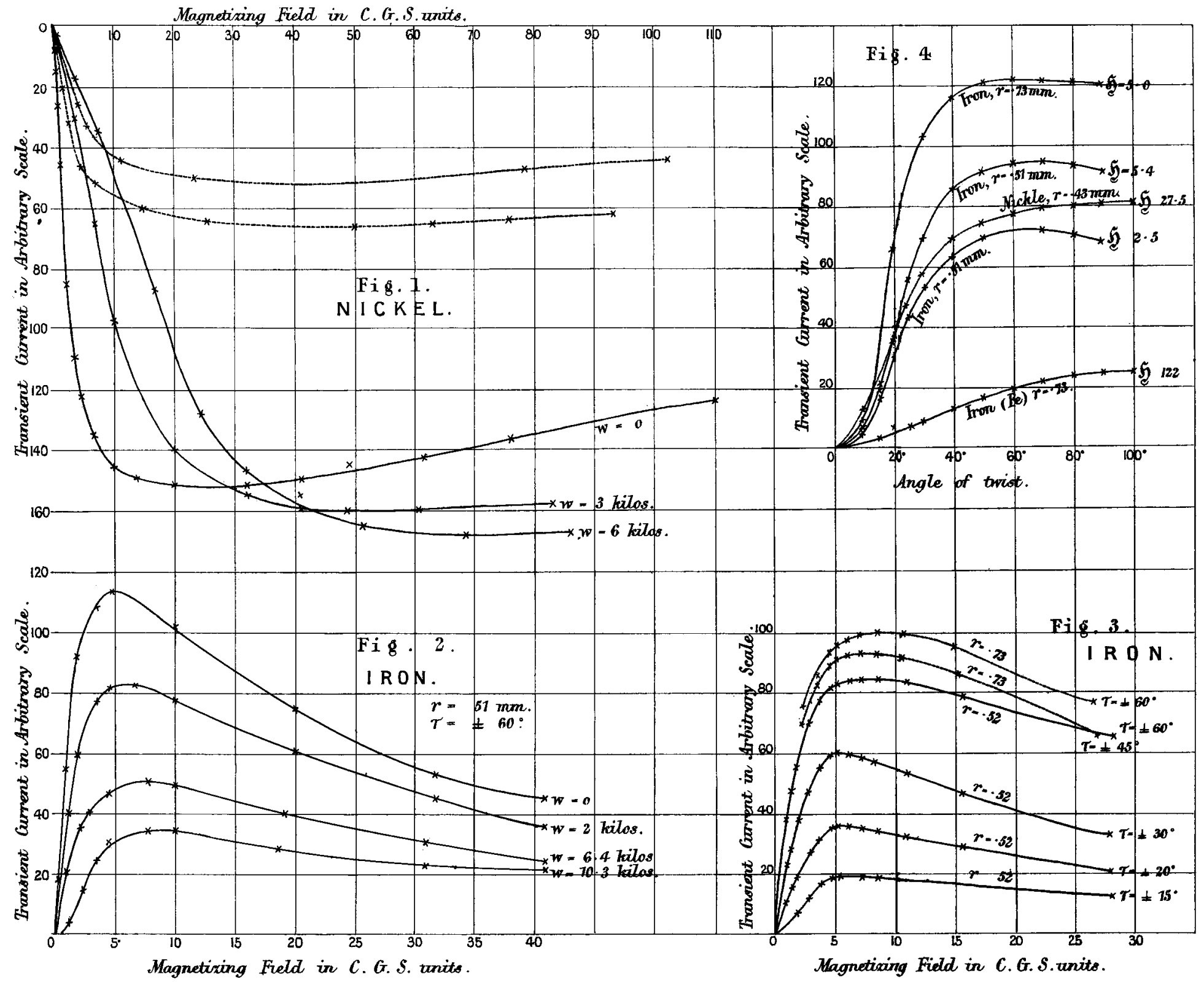




\section{H. Nagaoka on Transient Electric Current produced}

changed by loading, the maximum current is increased. At the same time, the point at which the current passes a maximum is shitted towards stronger field. The loading does not produce any remarkable change in the transient current.

Similar series of experiments were performed on an iron wire 1.02 millim. thick and 30 centim. long (July 8, 1888). The following Table gives the readings taken in different magnetizing fields :-

\begin{tabular}{|c|c|c|c|}
\hline \multicolumn{2}{|c|}{ With no load on. } & \multicolumn{2}{|c|}{ Loaded $6.4 \mathrm{kgs}}$. \\
\hline $\mathfrak{\$}$. & $\begin{array}{c}\text { Reading of } \\
\text { ballistic } \\
\text { galvanometer. }\end{array}$ & $\mathfrak{W}$ & $\begin{array}{l}\text { Reading of } \\
\text { ballistic } \\
\text { galvanometer. }\end{array}$ \\
\hline $\begin{array}{r}\cdot 34 \\
1 \cdot 1 \\
1 \cdot 8 \\
3 \cdot 6 \\
4.7 \\
6 \cdot 8 \\
10 \cdot 0 \\
20 \cdot 1 \\
31 \cdot 8 \\
41 \cdot 0\end{array}$ & $\begin{array}{r}18 \\
55 \\
92 \\
109 \\
114 \\
108 \\
103 \\
74 \\
53 \\
44\end{array}$ & $\begin{array}{c}\cdot 34 \\
1 \cdot 0 \\
2 \cdot 1 \\
2 \cdot 8 \\
4 \cdot 7 \\
7 \cdot 9 \\
10 \cdot 0 \\
19 \cdot 2 \\
31 \cdot 0 \\
41 \cdot 0\end{array}$ & $\begin{array}{l}45 \\
\mathbf{2 1} \\
36 \\
40 \\
47 \\
50 \\
49 \\
39 \\
30 \\
24\end{array}$ \\
\hline
\end{tabular}

These and two others are shown graphically in fig. 2. A glance at these curves will show that the transient current at first increases rapidly as the field is increased, but soon reaches a maxinuum and then begins to diminish gradually. The application of longitudinal stress diminishes the current, while at the same time the maximum point is transferred towards higher magnetizing field.

Comparing the results obtained for nickel and iron, we notice a peculiar difference in the behaviour of these two metals. The current which is produced by suddenly twisting the wire in the magnetizing field is, in the first place, opposite in direction. The direction* of the current in nickel is such that, the twist being applied like a right-handed screw, the current flows from south to north. In iron it is from north to south. This singular fact was also noticed later by Herr Zehnder.

In the experiments hitherto described the magnetizing force was gradnally increased, and the transient current produced by suddenly twisting the wire at different magnetizing

* See Note by Sir W. Thomson appended to this paper. 
fields was observed. There we see that both in iron and nickel the first increase of the field gives rise to rapid increase of the transient current. In unstretched iron this current attains its maximum strength at a field of about 5 C.G.S. units. It then gradually decreases as the field is further increased. In nickel of nearly the same length and thickness as the iron this current attains its maximum value very slowly, so that it is difficult to ascertain precisely the strength of the field at which this point is reached. Moreover, this maximum, though not very distinct, occurs at a magnetizing field far greater than that for iron.

The application of longitudinal stress produces opposite effects in the transient current in iron and nickel. The transient currentdue to sudden twist in iron always decreases when acted upon by pulling stress, whereas in nickel it diminishes in low magnetizing field, but beyond a certain strength of the magnetizing force the current in stretched wire attains greater value than in the unstretched wire. Thus the maximum transient current in nickel increases with the amount of longitudinal stress.

The effect of pulling the wire changes, not only the amount of the current, but also the strength of the field at which the current attains its maximum value. The effect is similar in both iron and nickel, although the amount of shifting of maximum in the former is less than in the latter.

That the transient current produced in twisting iron wire reaches a maximum was first noticed by Professor Ewing; the method of procedure in his experiments being different from the one here described. He measured the current produced in a twisted wire by reversing the direction of the magnetizing force. In the present experiment the current produced by twisting the wire was observed. In one of Professor Ewing's experiments the transient current induced in an iron wire 34 centim. long and 1 millim. thick, and twisted through $60^{\circ}$, passed a maximum when the strength of the field was 15 or 16 C.G.S. units. The wire used in the present experiments cannot be much different from the one used by Professor Ewing. The transient current attained its maximum value for $\mathfrak{S} \fallingdotseq 5$. Whether the discrepancy between these two results is due to the quality of iron wire or to the difference in the method of procedure, is a question not easily to be decided.

A simple glance at the results hitherto obtained will show the similarity between the phenomenon here investigated and the Wiedemann effect. In the latter phenomenon the twist produced by magnetizing a circularly magnetized iron wire 


\section{8}

H. Nagaoka on Transient Electric Current produced

is in opposite sense to that of nickel. Moreover the maximum twist in iron oceurs in lower magnetizing field than that in nickel. These facts closely resemble the transient current produced by twisting nickel and iron wires. In fact Professor J. J. Thomson* has shown that the existence of the Wiedemann effect necessarily leads to the production of electromotive force by twisting a longitudinally magnetized wire. According to Shelford Bidwell $\uparrow$ the Wiedemann effect in iron comes out in the same sense as in nickel when the magnetizing force is sufficiently increased. In order to see if there is any such similarity in these two phenomena, the transient current produced in high magnetizing field was examined.

Using the dynamo current, a magnetizing force of 300 or 400 units was easily obtained, and observations made with nickel wire are as follows (July 11, 1888) :-

Nickel wire $(r=\cdot 5$ millim., $l=30$ centim.).

\begin{tabular}{|c|c|c|c|}
\hline $\mathfrak{S}$. & $\begin{array}{l}\text { Reading of } \\
\text { ballistic } \\
\text { galvanometer. }\end{array}$ & Twist. & \\
\hline 333 & 55 & $\pm \stackrel{\circ}{60}$ & Under no load. \\
\hline 409 & 43 & \pm 60 & $"$ \\
\hline 333 & 66 & \pm 60 & Ioaded 3 kgs. \\
\hline 321 & 81 & \pm 60 & , 6 " \\
\hline 333 & 91 & \pm 90 & $" 6$, \\
\hline
\end{tabular}

The transient current in nickel wire diminishes with the increase of the magnetizing force, as will be seen from the readings given above. Even in a field of 300 units, the loading produces increase of the current-strengtb.

With an iron wire 1.46 millim. thick and 30 centim. long, and twisted through $60^{\circ}$, the following readings were taken:-

\begin{tabular}{|c|c|c|}
\hline $\mathfrak{S}$. & Reading. & Twist. \\
\hline 202 & 3.5 & \pm 60 \\
338 & Inappreciable. & \pm 60 \\
404 & $"$ & \pm 60 \\
550 & $"$ & \pm 60 \\
\hline
\end{tabular}

* See 'Application of Dynamics to Physics and Chemistry' p. 70.

$\dagger$ Phil. Mag. September 1886. 
The current produced in iron wire caused an appreciable deflexion of the galvanometer in a field of 200 units, and in the same direction as for lower fields. On raising the magnetizing force to 300 or 400 units, no current of measurable strength was produced. If the transient current becomes reversed in direction, the deflexion of the galvanometer becoming null in field of 300 units, an appreciable throw of the mirror should have been noticed in the opposite direction for $\mathfrak{S}=400$ or $=500$. Judging from the fact that no such change is observed, it seems probable that the current never becomes reversed even by further increasing the magnetizing force. The current thus appears to decrease asymptotically with the increase of magnetizing field. Professor Ewing also arrived at a similar conclusion.

The next point to be investigated was the effect of various amounts of twist on the transient current. There are two ways of examining the proposed problem. We may either vary the magnetizing field, while the twist is kept constant, and work out separately for different twists ; or we may keep the magnetizing force constant while the twist is made to vary.

Both these cases have been tried. The first case was tried with iron wire of different thicknesses, and the result is shown graphically in fig. 3 . The thinner wire was twisted through $\pm 15^{\circ}, \pm 20^{\circ}, \pm 30^{\circ}$, and $\pm 60^{\circ}$ (September 25, 1888). All these curves show that the current increases with the increase of twist. The maximum point remains nearly in the same magnetizing field for three small twists, but is shifted toward stronger field as the twist is increased. A similar tendency will also be noticed in the curves obtained for the wire of $\cdot 73$ millim. radius (September 22, 1888). The rate of decrease of the current as the field is increased becomes more rapid for the thick than for the thin wire.

Similar experiments performed on nickel wire of 0.43 millim. radius are shown graphically in fig. 1 (dotted lines). They are for the twists of $30^{\circ}$ and $60^{\circ}$ respectively. The increase of the current with the increased twist is quite apparent, but nothing definite can be said about the shifting of the position of maximum transient eurrent. After a certain strength of the magnetizing force, the current increases so gradually, that without very delicate measurement it is difficult to know exactly where the maximum point is situated.

To examine how the current increases with the increase of twist, I had recourse to the second mode of investigation, i.e.,

Phil. Mag. S. 5. Vol. 29. No. 176. Jan. 1890. 


\section{H. Nagaoka on Transient Electric Current produced}

changing the amount of twist while the magnetizing force is kept constant.

The following Table gives the readings of the first swing, in weák as well as strong magnetizing fields.

Iron Wire $(r=\cdot 51$ millim.
$l=30$ centim., $\mathfrak{S}=2 \cdot 45)$.
\begin{tabular}{|c|c|}
\hline & $\begin{array}{c}\text { Reading of } \\
\text { ballistic } \\
\text { galvanometer. }\end{array}$ \\
\hline 10 & $4 \cdot 0$ \\
10 & $15 \cdot 9$ \\
20 & $30 \cdot 2$ \\
25 & $43 \cdot 4$ \\
30 & $52 \cdot 9$ \\
40 & $63 \cdot 5$ \\
50 & 68.7 \\
60 & $71 \cdot 7$ \\
70 & $70 \cdot 7$ \\
80 & $70 \cdot 3$ \\
90 & $68 \cdot 8$ \\
\hline
\end{tabular}

$$
\begin{gathered}
\text { Iron Wire }(r=\cdot 73 \text { millim., } \\
l=30 \text { centim., } \mathfrak{H}=112) .
\end{gathered}
$$

The results of these and other experiments (September $22-26,1888$ ) are plotted in fig. 4.

Examining the curves obtained in weak magnetizing fields, we notice that the transient current increases with the increase of twist at first very rapidly, but after passing the "Wendepunkt" becomes very gradual. The current ultimately attains maximum strength, and then begins to diminish. In a strong magnetizing field the current is greatly diminished, and the curve becomes less steep. The increase goes on slowly with the increase of twist up to the maximum. Comparing the results obtained in different magnetizing fields, we notice that the twist for which the current is maximum becomes greater as the magnetizing force is increased. In fact the maximum for the wire of radius $\cdot 73$ millim. occurs when the twist is about $\pm 60^{\circ}$ for $\mathfrak{\mathfrak { Y }}=5 \cdot 0$, while for $\mathfrak{S}=112$ the twist of $100^{\circ}$ is barely sufficient to make the current reach the maximum strength.

With nickel wire treated in the same way as above, the following readings were taken (October 1, 1888):- 
Nickel Wire $(r=0 \cdot 43$ millim., $l=29 \cdot 4$ centim., $\mathfrak{S}=27 \cdot 5)$.

\begin{tabular}{|c|c||c|c|}
\hline$\tau$. & $\begin{array}{c}\text { Reading of } \\
\text { ballistic } \\
\text { galvanometer. }\end{array}$ & $\tau$. & $\begin{array}{c}\text { Reading of } \\
\text { ballistic } \\
\text { galvanometer. }\end{array}$ \\
\hline 10 & 13 & 50 & 74 \\
15 & 21 & 60 & 77 \\
20 & 35 & 70 & 79 \\
25 & 46 & 80 & $79 \cdot 5$ \\
30 & 57 & 90 & $80 \cdot 3$ \\
40 & 69 & 100 & $80 \cdot 5$ \\
\hline
\end{tabular}

The result is plotted in fig. 4 by dotted lines, where the ordinates are measured upwards for convenience, although they are actually below, as in fig. 1. The general feature of the curve does not differ much from those obtained for iron wires. The increase of the current beyond the "Wendepunkt" takes place very slowly, but it does not reach a maximum even for the twist of $100^{\circ}$. If the maximum exists, it must be for a larger angle of twist.

It has been remarked by Professor Ewing that the production of the transient current is a natural consequence of Sir William Thomson's * discovery, that æolotropic stress gives rise to an æolotropic magnetic susceptibility in iron. By twisting the wire, the lines of induction, originally parallel to the axis, are changed into belices. The component in the plane section, normal to the axis of wire, induces the transient current above described. Taking the Villari reversal into consideration, he also explained why the transient current in iron does not flow in the opposite direction, when the magnetizing force is greatly increased.

The development of æolotropic susceptibility by twisting the nickel wire, will similarly explain the production of transient current in that metal. The stress on twisting the wire is equivalent to extension and compression along lines perpendicular to the radius, and inclined at $45^{\circ}$ to the normal plane section. According to the experiments of Sir William Thomson $\dagger$ and Professor Ewing $\ddagger$, the susceptibility in iron

* Phil. Trans. 1878; or 'Mathematical and Physical Papers,' vol. ii.

+ L.c.

$\ddagger$ Phil. Trans. 1888. 
is, by stretching, rendered less in the elongational line than in lines perpendicular to it. The result is that the lines of induction of twisted wire are no longer straight, but are changed into helical lines. They are inclined toward the direction of relatively increased magnetic susceptibility. The direction of the transient current will be thus determined by that of compression. In iron, on the contrary, the direction of the current is that corresponding to stretching *'. Consequently, the direction of the current in nickel must be opposite to that in iron.

In nickel there is nothing corresponding to Villari reversal in iron. The magnetization of nickel is always diminished by stretching, while it is increased by compression. The consequence is that the circular component of the lines of induction is always on the increase as the twist becomes greater. This will account for the reason why the transient current does not reach a maximum even when the angle of torsion amounts to $100^{\circ}$.

Further investigations on the subject will be pnblished in the Journal of the College of Science, Imperial University, Japan.

Tokyo, Oct. 17, 1889.

[Note on the Direction of the Induced Longitudinal Current in Iron and Nickel Wires by Twist when under Longitudinal Magnetizing Force. By Sir W. Thомsоn.

To avoid circumlocutions suppose the iron or nickel wire to be vertical, and the magnetizing current to be in the opposite direction to that of the motions of the hands of a watch held with its face up. The undisturbed magnetization is downwards $t$. Now suppose a right-handed twist to be

* For explanation of this see Note by Sir W. Thomson added below.

+ Much of circumlocution is avoided. and of clearness gained, throughout dynamics and physics, by introducing the substantive noun ward (as has been done by my brother Prof. James Thomson in his lectures on Engineering, and in lithographed sheets put into the hands of his students, in the University of Glasgow) to signify line and direction in a line; - that which is represented ordinarily by a barbed arrow. Taking advantage of this usage $I n o w$ define the ward of magnetization as the ward in which the magnetizing force urges a portion of the ideal northern magnetic matter or northern polarity. By northern polarity, I mean polarity of the same kind as that of the earth's northern hemisphere. It is that which is marked blue by Sir George Airy to distinguish it from southern magnetic matter or southern polarity, which he marked red. According to a usage condemned 300 years ago by Gilbert, but not yet quite dead, English instrument-makers still sometimes mark with an $\mathrm{N}$ the true south pole, and with an $S$ the true north pole, of their steel barmagnets. All confusion due to this unhappy mode of marking magnets is done awry with by Sir George Airy's red and blue. 
given to the wire. Its elongational spiral is right-handed, and its contractional spiral is left-handed. If the substance is iron, the lines of magnetization become left-handed spirals ; if nickel, right-handed. Now a downward current, in the downwardly magnetized wire, would, by the superposition of circular magnetization in the direction opposite to that of the hands of a watch, cause the lines of magnetization to become left-handed spirals. Hence the sudden right-handed twist induces in iron a current upwards, in nickel a current downwards. Thus we have the following simple specification for the directions of the induced longitudinal currents in the two substances, without reference to "up " or "down."

From any point, P, on the surface of the wire, draw samewards parallels to the current in the nearest part of the magnetizing solenoid, and to the direction of the induced longitudinal current. Draw a helix through P making an acute angle with each of these lines. This helix is of same name as the elongational helix for iron, and as the contractional helix for nickel. -W. T., Dec. 21, 1889.]

\section{Proceedings of Learned Societies. GEOLOGICAL SOCIETY.}

[Continned from vol. xxviii. p. 493.]

November 20, 1889.-W. T. Blanford, LL.D., F.R.S., President, in the Chair.

THE following communications were read :-

1 1. "On the Occurrence of the Striped Hyæna in the Tertiary of the Val d'Arno." By R. Lydekker, Esq., B.A., F.G.S.

2. "The Catastrophe of Kantzorik, Armenia." By Mons. F. M. Corpi.

The village is 60 kil. from Erzeroum, and 1600 metres above sealevel. Subterranean noises and the failure of the springs had given warning, and on 2nd August last part of the "Eastern mountain" burst open, when the rillage, with 136 of its inhabitants, was buried in a muddy mass.

The anthor described the district as formed of Triassic, Jurassic, and Cretaceous strata, subsequently broken up and torn by granitic, trachytie, and basaltic rocks, which overlie or underlie the Secondary rocks, according to the nature of the dislocation.

The flow was found to have a length from east to rest of 7-8 kil., with a width ranging from 100 to 300 metres, and the contents were estimated at 50,000,000 cubic metres. It appeared as a mass of blue-grey marly mud, which, after the escape of the gases, solidified at the top; the inequalities projected to the extent of 10 metres. The site of the village was marked by an elevation of the 